\title{
United Kingdom
}

\section{"Beatles Documentary"}

\section{Decision of the High Court of Justice of England and Wales (Chancery Division)}

\section{July 2015 - Case [2015] EWCH 1853(Ch)}

Sony/ATV Music Publishing LLC and Sony/ATV Music

Publishing (UK) Limited v. WPMC Limited and Iambic

Media Limited (in liquidation)

US Copyright Act (Title 17 of the US Code), Sec. 107

(C) Max Planck Institute for Innovation and Competition, Munich 2016

Keywords Fair use - US doctrine - Transformative use - Commercial use · Excessive reproduction

1. The inclusion of all eight songs performed by the Beatles during their concert at the Coliseum in Washington DC in a documentary video does not amount to fair use, since said performed songs are expressive works within the core of copyright protection; the use is a commercial one; the use is only partly transformative; the songs are reproduced in their entirety; the extent of the reproduction is excessive having regard to the transformative purpose; and to permit such use would be likely to damage the market for, or potential value of, the said songs.

2. Seeking a license to use copyright works does not negate a finding of fair use.

3. It can be fair use to copy the whole of the copyright work where this is justified by the transformative purpose, particularly but not exclusively if the copy is not a high quality one (e.g. where an image is reduced in size).

4. As such, more can be taken than just the minimum necessary. The amount taken must be reasonable, and thus not excessive. If no more is taken than is necessary, then that will be reasonable. 